\title{
ANALYSIS OF THE MAIN RADIOLOGICAL FINDINGS OF MAMMOGRAPHIES DONE IN THE BRAZILIAN UNIFIED HEALTH SYSTEM IN THE DISTRITO FEDERAL BETWEEN 2013 AND 2015
}

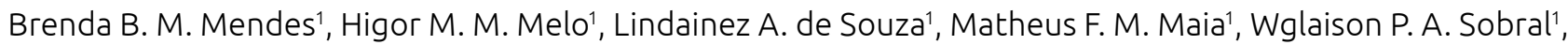
Fabiana C. Q. S. Anjos', Rafael S. Lima1, Priscila F. Barbosa ${ }^{1}$

${ }^{1}$ Centro Universitário de Gurupi - Gurupi (TO), Brazil.

Objective: To analyze the main radiological findings of mammograms performed in the Unified Health System in the Distrito Federal, correlating them with the age group. Methods: Cross-sectional study, in which the statistical analysis of variance was analyzed from 96,857 mammographic examinations performed in the Distrito Federal female patients of different age, race/color, from January 2013 to July 2015, being the data obtained from the Information System of Breast Cancer (SisMama). The chi-square test was performed with 5\% significance. Results: In the analyzed period, 96,857 mammograms were performed in women in the Distrito Federal, a predominant age group age 40-59 years (71.96\%). No radiological findings were found in $81.54 \%$ of the breasts. When comparing the laterality of the breast regarding the radiological findings, it cannot be compared with the significant statistic $(\mathrm{p}=0.75)$. The nodules that appear discretely predominate in the left breast, where as the microcalcifications were more found in the right breast. A total of 16,981 nodules, mostly between 11-20 mm and 1,352 microcalcifications were counted. Of the axillary lymph nodes found, 91.33\% were normal. Regarding BI-RADS, it was observed that $15.61 \%$ of mammographies were inconclusive (BI-RADS 0). Benign findings were found in $70 \%$ ( $\mathrm{n}=67,834$ ) of mammograms (BI-RADS 2). A total of 2,621 women (2.70\%) presented BI-RADS 4, 5 or 6 . Analyzing the age group, $57.21 \%$ of the women diagnosed with BI-RADS 5 had between $50-69$ years $(p<0,05)$, and $18.71 \%$ were between 40-49 years old. Conclusion: The close relationship between the radiological findings of the breasts and the age group of the patients leads us to recognize the importance of this examination for the early diagnosis and effective treatment. It was observed that in the great majority of mammograms performed no radiological findings were found. However, it is worth mentioning that the rate of women between 40-49 years diagnosed with BI-RADS 5 is considerable and worrying. This fact evidences the importance of the early screening of the malignant mammary disease through annual mammography from the age of 40, as recommended by the Brazilian Society of Mastology. 